\title{
Socialization as a Way for Improving Student Morality Behavior
}

\author{
Sharon Campbell-Phillips \\ Department of Education, University of the People, Pasadena, CA, USA \\ beautifulblushes@yahoo.com
}

\section{Abstract}

This paper explores whether the college level educational institutions in Bangladesh ensure scopes enough to teach, learn and exercise morality behaviors from the part of the learners. The data were collected from the fifty participants of targeted population of a ' $X$ ' college of Bangladesh. A semi-structured questionnaire was used as data collection instrument and both qualitative and quantitative data were intended to receive. The sample was selected through snowball sampling procedure from the ' $Y$ ' department of ' $X$ ' college. ' $Y$ ' department was selected randomly. Then, data was analyzed on the basis of ratio and nominal scale to analyze the data.
Keywords

morality behaviors, academic performances improvement; students, socialization; Bangladesh

\section{Introduction}

Morality behaviors can never be dissuaded from practicing in every respect of life as Schonfeld et al. (2019) has posited the idea that morality is the ecliptic and the first 'solar ladder' (to move human life in a pure and sophisticated way) (p.5). This pure and sophisticated way of human thinking and behavior is immense for a society which will extend to a greater nation. These authors having speculated on necessity of Ethics and values for the sustainable development of a nation. And students are to be the torch bearers of sustainable developments for a nation as today's youth is tomorrow's national builder in this and that ways. Highlighting the necessity of the youth to build a nation, Mikhail (2015) has referred to a quotation by former secretary general of UN Baan ki Moon where the author has quoted "Let us acknowledge and celebrate what youth can do to build a safer, more just world" (para. 5). This reference fosters the idea that the youth should build (i) safer and (ii) just world. And a youth learns what is just if they are ethical in thinking and moral in behavior (Mikhail, 2015). This fosters that the exercise of morality behavior among the students (who can be addressed as youth) is necessary. A learner is influenced with family, environment, and educational institutions where they learn every behavior appropriate for the harmony, peace and well-being of the society. According to Frederick Froebel, 'Children are the garden plants. The teacher is his gardener. The task of the teacher is to carefully raise the seedlings. It is the duty of the teacher to develop honest and social qualities that are hidden in the child ' (Referenced from Joyce and Weil, 2003). Teachers have been characterized as catalysts of behavior molding among the learners which applies that teachers play roles greatly on the learning and improving of morality behaviors among the learners. One of the great pursuits of knowledge distribution is teaching. Throughout the ages, teachers have played a role in the formation of societies with human and moral values. Confucius, the ancient religious leader of China, says, "Teachers will be the source of knowledge and wisdom. He will be an ideal ruler " (The reference taken from Cartwright, 2012). 
According to Siahaan, et al (2020) in a study done on The Effect of Scientific Approach and Interpersonal Interaction of Islamic Education to Student Characters in Integrated Islamic School Al Hafiz Langkat District, Students have the broadest opportunity to express their thoughts, feelings, attitudes, and experiences. But students still pay attention to scientific attitudes and responsibilities, and (3) Students are encouraged to always think analytically and critically. Accurately in understanding, identifying, solving problems, and applying learning materials. The scientific approach is very focused on students in the learning process. The cognitive process of students will develop because students are directly involved in learning both in the classroom and outside the classroom. In order to achieve their perceived goals, teachers need to implement programs. Wulandari, et al (2020) in their article, The Influence of Cooperative Learning Models and Learning Motivation on the Skills of Reading Students in Elementary School 101883 Tanjung Morawa Sub-District, states that "The learning method Cooperative Integrated Reading and Composition-CIRC (Integrated Cooperative Reading and Writing) is a form of learning originating from John Dewey, this learning model is the most complex model. Piaget assumes that knowledge is not static but continuously grows and changes as students face new experiences that force them to build and modify new experiences. CIRC type of cooperative learning in terms of language can be interpreted as a cooperative learning model that integrates a reading as a whole and then composes it into important parts."

Now the question of 'what is morality behavior?' is relevant to specify in order to identify which the student morality behavior are. Gert and Gert (2017) have specified the morality behavior as the rational, correct behavior which is socially accepted and the aim of this socially accepted behavior is harmony and peace in the society. Accordingly, Weissbourd (2003) has marked on the issues of (i) the moral behavior of students, and (ii) the duty of the teachers to teach moral behaviors to the students. The author has said that public holds the belief on the fact that educational institutions should ameliorate greed, delinquency and disrespect prevalent among the students. Thus the author has tried to characterize student moral behavior but not limiting only on these things. The purpose of student moral behavior learning is to being a complete human being with ethical, moral, emotional and rational aptitude (p.10).

This paper is built on three key concepts, such as; (i) the idea of student morality behavior, (iii) the way of improvement of the student morality behavior and (iii) the concern of such improvement in the colleges of Bangladesh. This paper tries to evaluate the scope and opportunity of teaching and learning of morality behaviors in the colleges of Bangladesh. This paper tends to sort out the way how educational institutions can thrive to ensure morality behavior exercise in class rooms only if the remedial steps is required. The colleges of Bangladesh have been regarded as the areas of case studies because the recent rise of intolerance, scandals, killings of fellow mates among the students of college levels of Bangladesh are apparent. Kamol (2019), a reporter of an English daily, interviewed one of reputed university vice-chancellors where the vice-chancellor retorted, "Unfortunately, fellow feeling and respect for fellow students are often missing nowadays. Often lack of respect for the teachers is observed, which not a good sign is in any given society," (para. 8). This prevailing scenario fosters the idea that the colleges of Bangladesh cannot address the necessity of morality behavior and make a way out to nourish these in educational institutions. This prevailing gap made to search for solution of the hypothesis that 'The colleges of Bangladesh lack of teaching and improving morality behavior among the students of Bangladesh'. 
Kamol (2019) has also reported that the alphabet teaching in the past began with moral teachings which the texts of modern time are missing. The spread of science and technology, modern communication system, internet and mobile connectivity have made the educational contents paradigm shift. So, the educational system, institutions and teachers have greater roles to make the learners on track as the role of the teacher is very important and effective in creating moral values among the students. In any student's life, the role of the teacher is very much influenced by the family or the parent. Teachers are the conscience of the country and the great craftsman of the enlightened nation and human resources. When a human child reaches the age of school or sometimes even before, he or she comes in contact with the teacher at any stage throughout the whole life and it will have a permanent effect in their life.

The advancement of education is to be measured with exterior and interior improvement of a student which the educational system of Bangladesh is lacking behind. The students are being brought up with high performances in sciences and technologies as well as moral and ethical impairment which disrupts the true purpose of education (Kamol, 2019). However, the paper tends to focus on the role of the teachers in this era to make the students morally living along with the academic performance as academic performance is not only achievement of medals but also improvement of moral behaviors.

\section{Review of Literature}

The term 'Morality behavior' is an embedded word of (i) moralization and (ii) behavior. The behavior which has been moralized can be termed as 'Morality behavior'. Behavior is any type of action and the preceding of morality before behavior specifies the type and ways of behavior. Thus, the morality behavior needs to be clarified with the help of literatures where the researchers as well as thinkers have tried how to define morality and behavior.

The term 'Morality' is an abstract one by its own nature. Moreover, this term has been viewed and reviewed by the philosophers, psychologists, thinkers from their perspectives. Gert and Gert (2017) has defined 'Morality' on the basis of two points of view, that is; (i) descriptive and (ii) normative. The descriptive point of view describes morality as a code of conduct, or correct behaviors, set by the religions or society which the community people have to follow in order to live in that society with symmetry. But the second point of view mostly depends on the individual choice. The action which seems rational to the individual gets abode in their mind and they practice these in their everyday life terming them as moral practices (p.1). Thus morality gets a specification depending on the individual choices which emerge through the rationality that every person possesses.

Here, Gert and Gert (2017) has clarified the fact that individual cognition assists persons in adopting morality behavior. But this ideation creates a vacuum as to who are those persons that apply or can apply cognition to determine which is moral. Moreover, the practice of every individual morality creates disharmony in a society that can lead to collapse of society, at least a community. This projects the thought of agreeing on descriptive point of view as the morality behavior must possess a universal, or national, or a social, or community code which the people across that circle follow.

It is now relevant quarry who determines the code of morality behavior. Brent \& Evelyn (2017) states that it is very tough to state the determinants of code of morality behavior in this era of multiculturalism (para. 4). They have initiated a question regarding the issue of the Jew cleansing as Jew were the part of German morality code of conducts before the WW II, but why they were subjugated to concentration camps is the question 
that shakes the appropriateness of code of morality behavior set by the society. Yet, they have the consent on few major sources of determining morality. They agree on (i) 'Cultural Relativism' and (ii) 'Divine Command Theory' along with (iii) 'Moral Subjectivism' and (iv) 'Ethical Egoism' (para. 3). Social as well as religiousinstitutions come to the fore if the sources of institutionalization is considered.

Education is a lifelong process. More specifically for the concern of the aims and scope of this paper, the education which is institutionalized by schools, colleges and universities is being considered for review. Little (2014) has evaluated such kind of institutional education as it is a process of socialization by educating learners with 'cultural expectations and norms' (p.494). The teachers, textbooks as well as the classmates reinforce these into a learner. Morality behavior is one of the cultural expectations and norms. Thus, educational institutions has turned to be an entity of educating morality behavior. Now at the forefront of the 21 st century, a qualifying term has been added before education and it sounds quality education. United Nations has for the first time addressed education with such emphasis that the idea of 'quality education' has been set as SDG-4 (Sustainable Development Goal) among the 17 goals which is set to be met by the member countries by 2030. (i) Inclusiveness, (ii) equitability and (iii) longevity all through life have been made as the defining characteristics of quality education. Slade (2017) has referred that quality education includes a child's mental, emotional, moral, physical and cognitive development so that it becomes an active citizen of the nation who will uphold peace, harmony and prosperity to their society. However, the 21 st century education or quality education, how we explain the term, cannot cease from the way of educating morality to nourish moral and disciplined behavior among the learners.

Bidwell (1972) establishes the idea in his paper that values and moral behaviors can be learned through proper socialization as socialization is the sum total of values and moral behaviors which are representational in the context of community or society. Educational institution is one of the greatest industries that fosters socialization of a member (Little, 2014). Thus, moral grounding, socialization and educational institutions are interlinked as well as intra-linked with one another. Thus, the role of an educational institution to the process of socialization through imparting morality behavior to the learners can never be constrained.

Pels and Ruyter (2012) have worked on radicalization of youth and found education as well as socialization have great influence on radicalization and they have contended that the moral and religious values of the parents and teachers help youth inculcate that ideology imposed on them (p. 315). Here, the inculcation of moral and ethical beliefs has been shown depending significantly on the teachers apart from their parents. And a teacher exposes any sort of ideology to the students in the classes with the help of textbooks. Thus, the class lectures of a teacher as well as the messages of textbooks exposed by the teachers to the students become the greatest media for a teacher which help them guide the learners. Here, the willingness of the teachers or the competence of them as well as the valuable textbooks as resources to learn moral behavior are emergent.

The previous literatures have strived to clarify the idea of morality, moral behavior, the role of the educational institutions and teachers in order to inculcate moral behavior in the learners. And the literatures have also made connections the process of institutional socialization with all these behavioral moldings. It fosters the idea that institutions pave the way to socialization and the learners learn the moral codes of conducts prevalent in the society through this process. But the educational institutions have also pragmatic point of views on the necessity for creating human resources amid the challenges of the globalized competitions posited through information and technology. From this point of view, the 
necessity and worth of an institution based on the academic performances on the part of the learners are to be granted as significant. It exposes the reality of an educational institution as a creator of academic performers. Now, the point of discussion is whether the teaching of morality behavior and academic performance align, whether schools dissuade the path of morality behavior teaching in order to emphasize only on the academic performance.

According to Kassarnig et al. (2018) academic performance has two dimensions, (i) Individual academic performance and (i) cumulative academic performance. Individual academic performance relies mostly on the efforts of the learners and their familial supports. But cumulative academic performance relies on the efforts of the institutions. Kassarnig et al. (2018) have studied on the issues of academic performances and found that socializations of the learners help to increase academic performances. The learners who are more active in socialization process initiated by the educational institutions have been able to show satisfactory academic performances as these learners have already adopted shared learning and are akin to group work, distributed studies. This study has recommended that the way of raising academic performance among the learners are to involve the learners in more socialization process as this process helps to raise academic performances.

Thus the idea of teaching morality behavior as well as that of raising academic performance fosters the urgency of socialization process from the part of the educational institutions. The institutions have every possibility to impact positively on the issues of academic performance and morality behavior. Morality behavior teaching is impossible without proper socialization and proper socialization results in higher academic performances (Pels and Ruyters, 2012; Kassarnig, 2018). And all these are embedded with the terms of quality education highly emphasized through the 'Goal- 4 of Sustainable Development Goals' proposed by the United Nations which is to be met by 2030 .

But all these promising notes fail if the situation of the morality behavior teaching, learning and practicing are considered in the context of the education of Bangladesh. Ray (2013) has studied on this issues in the University of Dhaka and reported the educational system of Bangladesh necessarily fails to address the morality education along with various general and technical subjects (p.7). Moreover, the paper finds that $98 \%$ responded felt dissatisfaction while reporting to the provision of morality education and morality practice in the campus or classrooms and $95 \%$ respondents agreed on the fact that the existing curriculum has faults which cannot address the necessity of moral education. It is their opinion to revise the curriculum without delay as they report that extortion, delinquency, teasing and disrespect are harnessing rapidly due to the lack of moral education ( $\mathrm{p} .47)$. This provided the fodder for the researcher to find out whether the learners in the college level of Bangladesh feel the same and whether they are properly socialized by educational institutions apart from only textual provisions.

\section{Research Methods}

The few major questions developed the ground of this paper as to (i) the scope of learning morality in the classroom context, (ii) the response of the students regarding the availability of learning and practice of morality in the class room and (iii) the way out of checking student morality deterioration through institutionalization. In order to study on the mentioned concerns, the researcher intended to measure the frequency of the availability/unavailability of learning-exercising of morality in classroom context, and fostered description of the findings. According to Bernard (1994) Qualitative method describes "a situation, phenomenon, problem or event" on nominal scale approach (p.2) .This paper studies the prevailing situation on the lessons of morality in the classrooms and 
it tries to analyze whether the learners are satisfied with the arrangements from the part of the institutions so that the learners can exercise morality in institutions. Again, some close ended questions helped to collect data that aimed to quantify the frequencies of responses on the issues of (i) institutional provisions of morality lessons, (ii) the scope of students to practice morality in institutions like "yes, no, satisfied, dissatisfied, etc." These data will help to quantify how many teachers feel satisfied or unsatisfied with the total arrangements of multimedia in that college. These types of data present the quantity of the responses.Thus, the paper incorporates triangulation of more than one methods, that is; qualitative and quantitative methods for the purpose to identify the number of the respondents aggrieved as well as to realize conception of morality behavior that the respondents feel to be and to do.Teddlie and Tashakkori (2009) have proposed that the triangulation of methods is a positivist outlook in the fields of research and it is frequently sought for method as it helps to analyze both numeric and descriptive data in order to retain validity and reliability of the research (p.4).

\subsection{Selection of the Study Area}

The best part of research design is the selection of the study area. It is very critical in order to make the retrieved data representable, neutral and reliable. There are few major issues that a researcher should remember to select an area for study that (i) the study area must be general in characteristics so that the data collected from this area may represent the truth of the total area, (ii) The research area must be within the limit of time and resources of the researchers and research, (iii) the research area must be validated through the aim and scope of the research (Jokar, 2012). The researcher has selected a government college of Bangladesh situated in the city area as this type of college represents the students from various cast, color, creed, and socio-financial backgrounds that can be regarded as the representational college of Bangladesh containing the general tendencies prevalent in the students of Bangladesh. The selection of this ' $\mathrm{X}$ ' college has served the purpose of the researcher as the researcher had time and resources limitation to conduct the research. Thus, the consideration of time, resources and general representational characteristics of the learners made the researcher select this ' $\mathrm{X}$ ' college for the purpose of research.

\subsection{Selection of Respondents}

The study population is the target group on whom the findings of the research is generalized, and the controlled group or sample group is selected from that target group. Thus the sample group is a subset of a study population or universe. The larger the sample group is the little the chance of error and biasness. But time, resources and convenience assist mostly in choosing the manageable size of sample. Kenny (1987) has proposed a size of target group and controlled group as the 310 numbers of target group may be represented in the 50 numbers of controlled group (p.215). The graduate level of students have been considered as the target group for the study as convenience due to the availability of graduate students in this ' $\mathrm{X}$ ' college. There are nine departments and every department covers at least 300 to 400 students and the researcher used snowball sampling to reach at least fifty students among the 400 students of a specific department.It was hard to gather fifty students at a time and that let the researcher choose the technique of snowball sampling to reach them. A department was selected as the students of every department were equal in the characteristics of gender, age, regionalism, socio-cultural factors etc. Thus, the researcher is convinced of the generality of the department. This department was randomly chosen among nine departments. 


\subsection{The Research Instruments}

The data collection tool defines the Research Instrument. The research instruments include questionnaire and various scales. Data is prime concern for a research work and all the data is not required for a specific purpose in a research. It fosters the need for systematic procedures of data collection in order to ensure the reliability and validity of collected data. To make data credible, a tool is inevitable. Qualitative and quantitative research claim different types of data collection tools (Formplus, 2019). This research wages triangulation of mixed methods and the researcher has adopted a questionnaire of mixed quality. The researcher has adopted a questionnaire of ten questions which includes open ended questions which aimed at delving out qualitative data and close ended questions which posited to dig out the quantitative data.

\subsection{Data Collection Procedures}

Questionnaire Survey method has been used for this study to collect the primary data. A note was attached with the questionnaire where the researcher provided the aims and objective of the survey and the note also clarified how the researcher would interpret the findings without referring any proper name of the respondents. Thus, the respondents were assured of the confidentiality of their identity.Ten respondents who were interested to become the participants were chosen by the researcher from the ' $\mathrm{Y}$ ' department on availability basis. Then other respondents were collected and surveyed with snow ball data collection procedure. The responses were amalgamated within ten days. The initial ten respondents were highly trained up and motivated how to provide questionnaire and collect data so that maximum feedback might be ensured. A light type of reinforcement was ensured to provide to every respondent that assisted to retrieve $100 \%$ feedback from the reached participants.

\subsection{Techniques of Data Analysis}

The semi-structured questionnaire procreates both qualitative as well as quantitative data which claim analysis from multi-dimension. The quantitative data is presented through ratio scale and qualitative data has been made descriptive analysis. Through these multi- dimensional analysis, the state of the learning and exercise of morality behavior in the class room context and the way of checking deterioration of moral behavior was indicative.

\section{Results and Discussion}

\subsection{Findings}

The findings aim to clarify the prevailing conditions of the problems indicated at the very exposition of the paper. It is a way to prove or disprove the hypothesis of the paper. This paper has on the supposition that the college educational systems of Bangladesh cannot provide with morality education, morality behavior practice in classrooms (these conditions have also been identified through the reference of Kamol, 2019; Ray, 2013). Let the author expose the data collected from the real context to prove or disprove the hypothesis.

\section{a. The Prevailing State of Morality Behavior}

The very first five questions in the provided questionnaire to the study population aimed to delve out the extent of socialization in the context of both family and schools. Socialization is a process which begins from family and matures in the educational 
institutions which has been elaborated all through the reviews of literatures. But 24 (48\%) participants out of 50 responded that they do not prefer keeping in touch with relatives on a regular basis which presents a sort of indifference (Kamol, 2019) prevalent in the learners regarding the essence of familial bonding. Again, the significant number of respondents had opinion on the fact that the educational institutions of Bangladesh cannot provide with morality teachings as 32\% respondents had responded negatively and more $12 \%$ respondents had doubt on the opportunity of morality teachings in the classrooms though 96\% respondents believed on the necessity of morality behavior practices in the educational institutions.

Table 1. Cumulative Frequencies of Morality behavior practices

\begin{tabular}{|c|l|c|c|c|c|}
\hline SL NO & \multicolumn{1}{|c|}{ Questions } & YES & NO & N/A & $\%$ \\
\hline 1 & $\begin{array}{l}\text { Do you prefer keeping in touch with relatives } \\
\text { on a regular basis }\end{array}$ & 20 & 6 & \\
\hline 2 & $\begin{array}{l}\text { Ethics plays a role in obtaining students' } \\
\text { ability to socialize }\end{array}$ & 50 & 00 & 00 & \\
\hline 3 & $\begin{array}{l}\text { The ethical practices among the Bangladeshi } \\
\text { students are sufficient }\end{array}$ & 28 & 16 & 6 & \\
\hline 4 & $\begin{array}{l}\text { Can educational institutions teach morality to } \\
\text { the students }\end{array}$ & 40 & 10 & 00 & \\
\hline 5 & $\begin{array}{l}\text { Is it essential to keep morality behavior } \\
\text { practice in the classroom / educational } \\
\text { institutions }\end{array}$ & 48 & 02 & 00 & \\
\hline
\end{tabular}

\section{b. The Extent of Institutional Provisions of Morality Practice}

The next three questions were set to find out (i) whether the respondents were satisfied at the morality behavior of the students, (ii) whether the respondents were satisfied at the provisions of moral teachings designed by the curriculum and (iii) whether the respondents were satisfied at the availability of practice of morality behavior in the classroom situations. Let the triad sides of dissatisfaction ratio be shown through the Figure 1 where the $42 \%$ respondent responded dissatisfaction on the student morality behavior, $40 \%$ responded dissatisfied on the provision of morality in the curriculum. But the very dissatisfied factor was the unavailability of institutional provisions where the students cannot be provided by the teachers or college administrations with the scope of practicing of morality behaviors in the classroom and out of the classroom staying in campus. 


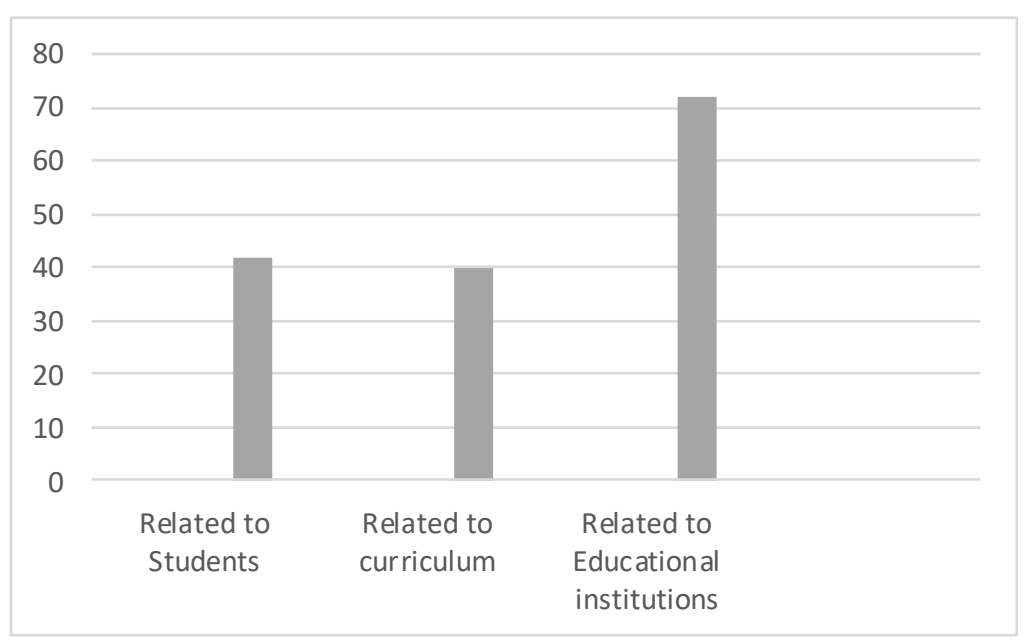

Figure 1. The Ratio of Dissatisfaction in three sides

\section{c. The Factors Related to the Causes of Moral Deterioration}

The last two questions were set as open- ended questions. These questions sought to find out the cause of moral degradation and the way to checking moral degradation among the students. The fifty respondents drew the attention to thirteen factors responsible for moral degradation among the students. Table 2 categorizes these thirteen factors and the frequencies of the respondents:

Table 2. The Reason for Moral Degradation

\begin{tabular}{|l|l|l|l|}
\hline S.L. No & $\begin{array}{l}\text { Number of } \\
\text { Respondent students }\end{array}$ & Reasons & $\%$ \\
\hline 1 & 5 & The social system & 10 \\
\hline 2 & 3 & Lack of values & 6 \\
\hline 3 & 3 & Disobedient to parents & 6 \\
\hline 4 & 3 & Foreign Culture & 6 \\
\hline 5 & 4 & Lack of family education & 8 \\
\hline 6 & 3 & Family feud & 6 \\
\hline 7 & 4 & Lack of family awareness & 8 \\
\hline 8 & 4 & Dishonest company & 8 \\
\hline 9 & 4 & Lack of religious knowledge & 8 \\
\hline 10 & 3 & Misuse of information technology & 6 \\
\hline 11 & 3 & Mobile phone abuse & 6 \\
\hline 12 & 6 & Social chaos & 12 \\
\hline 13 & 3 & Consumption of drugs & 6 \\
\hline 14 & 2 & None/ No answer & 4 \\
\hline
\end{tabular}

A qualitative question was conducted to get the reason of student moral degradation. Here every participant was independent to deliver the answer and no clue/hints was preset 4 students expressed the view that morality is deteriorating due to lack of family education. $5 \%$ of the total students think that lack of family awareness leads to degradation of morals. 7 students consider dishonest company to be the cause of moral turpitude. 5\% of students think that morality has been lacking due to lack of religious knowledge. $72 \%$ of students attributed the misuse of mobile phones and information technology to degrading morality. 
Three students consider social chaos as a cause of moral turpitude. The remaining five students blamed the use of alcohol as the main reason for the degradation of morality.

\section{d. The Factors Related to Checking Moral Degradation}

The very last questions tried to delve out the ways of checking moral degradation as the paper tended to come to a resolution of finding out a probable way of improving morality behavior among the students in a classroom context that will lead to these practices out of the campuses and even all through their lives. The fifty students indicated their responses on various ways which were categorized as (i) family responsibility, (iii) Student self- commitment to the society and (iv) educational institutions. Only 4\% respondents opined other ways to improve morality behaviors among the students.

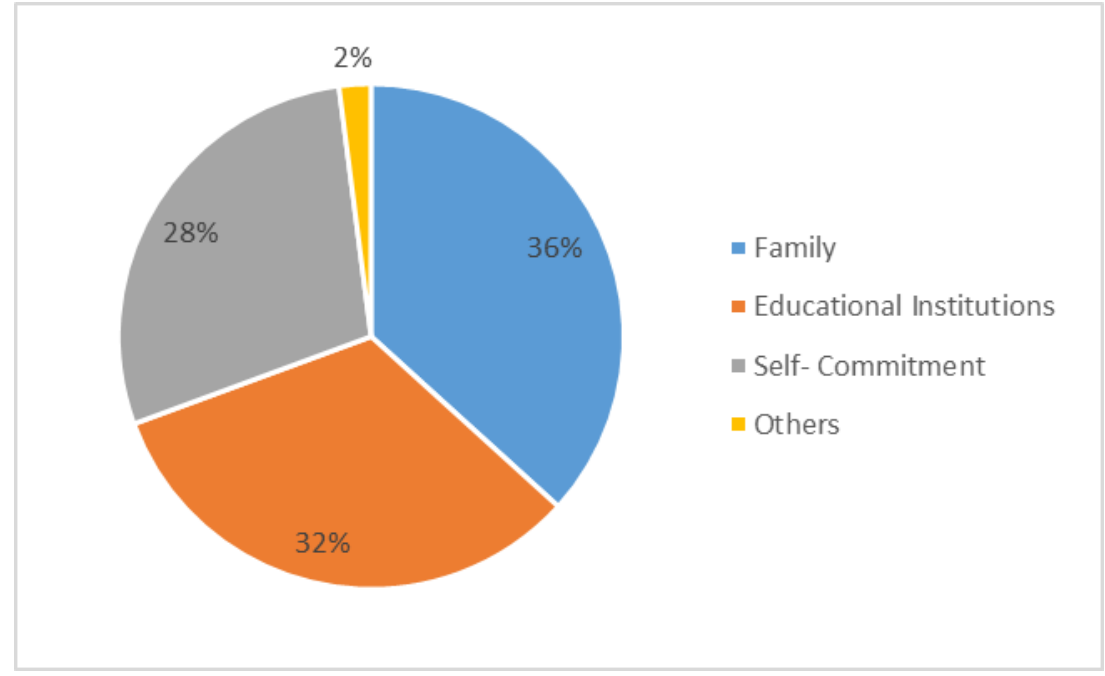

Figure 2. The Way of Improving Morality Behavior

\subsection{Discuission}

The study of the paper was set to justify the hypotheses of this research. The research aimed to defend and disprove the supposition of the paper indicated at the very exposition part of the paper. The literature reviewed for this paper indicated the way of study for the solution of the problem stated through the title of the paper. The literature revealed that socialization is the first process which a school follows or needs to follow in order to make bonding among the students. Then, this socialization will result in morality behavior learning with increasing ethical and legal practices among the learners. Thus, academic performance will expedite which will result in quality education. Again, the literature (Ray, 2013; Kamol, 2019) studies revealed that Bangladesh failed to address the practice of morality behavior as the curriculum was faulty, the institutions were not active.

Whether the institutions advance to teach morality behaviors is beyond questions. The literatures and the present findings suggest that the students want the institutions would accord these availability so that the learners can get scope enough practice morality behaviors in the classroom, in the campus. The findings suggest that 40 respondents $(80 \%)$ believe that the educational institutions have lots to do in order to improve the morality behavior of the students which has also been stated by Little (2014).

But the findings have also provided with the fact that $72 \%$ respondents believe the educational institutions of Bangladesh (Specially the institutions providing college level of education) cannot arrange any sort of practice which may help to improve the morality behavior of the students. Ray (2013) has also found the similar data on the lack of 
negligence of the educational institutions to make a way for practicing morality behavior and this author stated that ' institutions are being motivated to serve the commercial aspect of the society as well as the globe' (2013:85). But why the institutions are failing has its cause found through the study. The $40 \%$ respondents reported that the curriculum of Bangladesh is faulty in respect to the arrangement of moral teaching. Teachers as well as the educational institutions are more likely following the curriculum instead of revising the curriculum. Most of the colleges of Bangladesh follow the curriculum designed by the national authority which may create a hollowness.

The deep analysis of the Table 2 shows that the participants who were asked to answer the specific qualitative question "Write a reason for the students' moral degradation" responded verities types of answers. Among the fifty respondents, $12 \%$ drew attention to the "social Chaos" while 10\% responded that social system was the main factor for moral degradation. Other 21 students commented on another seven agents being the reasons for student morality degradation. Those were: Lack of values, disobedient to parents, effect of foreign culture, effect of family feud, misuse of information technology, misuse of mobile phone and drug addiction. Lack of family education, lack of family awareness, dishonest company and lack of religious knowledge were responded as causes of student morality behavior. From this analysis, one thing is notable that social disorder plays a great role in moral degradation. Disrespect to parents indicates the looseness of family bondage, chaos prevalent in society and social system (that provokes and inspires delinquency) are indicated as the pivotal causes of student morality degradation. More than one families constitute a society and various educational, social and political institutions inclusive in this society. Thus, the moral degradation points to the lack of proper socialization among the persons growing up in the society. According to Little (2014) educational institution is one of the greatest institution of society after family. If social disorder is claimed to be responsible of student moral degradation, the educational institutions need to be speculative on the issues of such types of student degradation.

The findings also suggest that $32 \%$ respondents believe that educational institutions can help improve the situations and 36\% respondents trusted on the necessity of family in this matter. A child gets socialized through these two social institutions. It fosters the idea that family and educational institutions are focus to dig out the cause and solution of student moral degradation.

\subsection{Implications of the Study}

This is a case study which was done on a specific college of Bangladesh. The findings revealed through the study from the fifty respondents of this indicated college prove the hypothesis that the educational institutions of Bangladesh lack the proper arrangements of teaching morality behavior education to the students. The curriculum is not up to the mark which proves the assumption of Ray (2013) and Kamol (2019). It indicates that the results of this research is representative and can be granted as proof in the case of Bangladesh. The national authority who revise and adopt curriculum for the nation can consider the results of this research in order to determine which needs to be focused on for the future curriculum. The college authority may consider this findings to reshape the activities of the institutions and to guide the teachers how to conduct the classes in order to improve the morality behavior among the students. But this paper has some limitations also. It collected data from the learners and did not include the responses from the teachers, college authority. Their responses may be considered here to come to a consolation of neutral data of the core reason of student moral degradation and the extent of necessity of classroom practice of improving morality behavior. The role of the family has not been 
justified here for improving student morality behavior. Other authors will have to do a comparative study on the role of family and schools for improving student morality behavior which this paper deliberately curtailed for the convenience and time. But the deliberate elimination of multi-dimension paved the way of exhuming the role of institutions, the lack of institution, and the necessity of socialization in terms of improving the morality behaviors among the students.

\section{Conclusion}

Teachers build students into real people. Social, culture, norms also have an impact on creating students' values. This values will be created among the student through the process of socialization. The findings project time and time again that the respondents were reluctant to keep regular contacts with the relatives and some of the respondents provided that integrity with internet, social media and mobile phones are few of the causes of moral degradation. An institution can focus on the issue of raising social connectivity among the students. Therefore, socialization programs should be organized regularly in all levels of education from elementary to university. This will create a solid foundation for students to have a sense of social responsibility and cultural values. As a result, they will avoid being misled. At the same time, they will develop mindfulness. The development of students' moral and human qualities is based on the triangular relationship of student, teacher and parent.

The development of human qualities is not so much through textbooks. In this case the surrounding situation plays a major role. Students learn about moral and human qualities from their surroundings which fosters the idea of social integrity and interaction among the learners.

In addition to the development of the moral education received by the students in education, social education and human qualities are learned. Students of different families have the opportunity to mix with students in education. Through this interaction, students learn and understand many things. Therefore, a healthy environment should be ensured in the educational institutions. In many cases, children may not be listening to their parents about anything. Therefore, in order to develop the moral, social and human qualities of the students, they must first have them inside the teachers. After parents, children consider teachers the way of life (Schonfeld et al., 2019). Although the educational system is within a boundary, the students get the greatest education in life as teachers try to teach and teach students about life. Proper instruction of the teacher plays a role in making the students as human beings with human qualities.

\subsection{Recommendations}

The objective of this paper was to find a way out so that the teachers, educational institutions or institutional authority may positively impact on the improvement of student morality behavior. The title suggested that a way will be directed to solve the problem prevalent among the learners and this dignified way is 'socialization'. The problem prevails and is increasing among the students due to their negligence of social connectivity. They are reluctant of keeping relational ties among the relatives which imped respect to all. In this event, the educational institution should arrange various events so that the learners can learn to assist others, learn in groups and showcase their achievements in groups. 


\section{References}

Bernard, H. R. (1994). Research Methods in Anthropology: Qualitative and Quantitative Approaches (2nd ed.). Thousand Oaks, CA: Sage.

Bidwell, C.E.(1972). Schooling and socialization for moral commitment. Interchange 3, 127. https://doi.org/10.1007/BF02145404

Brent M. and Evelyn (June 12, 2017). What Is Morality? Who Determines What is Moral, or How is it Determined? [BlogPost].meetup. A4. Retrieved at 20th January, 2020 from https://www.meetup.com/tampa-bay-thinkers/events/240285607/

Cartwright, M. (November 29, 2012). Confucius. Ancient History Encyclopedia.[BlogPost]. A4. Retrieved on 2nd February, 2020 from https://www.ancient.eu/Confucius/

Formplus (2019, December 17). 7 Data collection methods and tools for Research. [Blog Post].A4. Assessed in 10th February, 2020 from https://www.formpl.us/blog/datacollection-method

Gert, Bernard and Gert, Joshua. (2017).The Definition of Morality.The Stanford Encyclopedia of Philosophy, Edward N. Zalta (ed.), URL = $<$ https://plato.stanford.edu/archives/fall2017/entries/morality-definition/>.

Jokar Arsanjani, Jamal. (2012). Study Area Description. 10.1007/978-3-642-23705-8_3.

Joyce, B. \& Weil, M. (2003). Models of Teaching. Prentice Hall of India, pvt. (5th ed), New Delhi- 110001.

Kamol, E. (Sep 21, 2019). Moral, ethical degradation impairs education system: BUET VC. NEWAGE: Interview. Retrieved on Feb 15, 2020 from http://www.newagebd.net/article/85192/moral-ethical-degradation-impairseducation-system-buet-vc

Kassarnig, V., Mones, E., Bjerre-Nielsen, A. et al. (2018). Academic performance and $\begin{array}{llllll}\text { behavioral patterns. } & \text { EPJ Data Sci. } & 7, & 10 & \text { (2018). }\end{array}$ https://doi.org/10.1140/epjds/s13688-018-0138-8

Kenny, David A. (1987). Statistics for the social and behavioral sciences. Boston: Little, Brown. ISBN 978-0-316-48915-7.

Little, W. (2014). Introduction to Sociology (1st Canadian edition). OpenStaxCollege. Retrieved from https://opentextbc.ca/introductiontosociology/chapter/chapter16education/

Mikhail, A. (2015). Role of students in nation building" [Writer's contest 3]. Pulse.ng [BlogPost]. Retrieved on 15th February, 2020 from https://www.pulse.ng/communities/student/pulse-blogger-role-of-students-in-nationbuilding-writers-contest-3/x687yx6

Pels, T. and de Ruyter, D. J. (2012). The Influence of Education and Socialization on Radicalization: An Exploration of Theoretical Presumptions and Empirical Research. Child Youth Care Forum. 41:311-325. DOI 10.1007/s10566-011-9155-5

Ray, N. (2013). Education System and Sense of Moral Values: A Sociological Study Among The Students Of University Of Dhaka. This Advanced Research Paper is submitted to the partial fulfillment for the requirement of the degree of MSS: 2013. University of Dhaka. Retrieved from http://repository.library.du.ac.bd/bitstream/handle/123456789/1539/Nibedita\%20Ray .pdf? sequence $=1 \&$ isAllowed $=\mathrm{y}$

Character Education, Current Approaches to Moral Education. Education Encyclopedia StateUniversity.com.

Retrieved

from https://education.stateuniversity.com/pages/2246/Moral-Education.html 
Schönfeld, Martin and Thompson, Michael (2019). "Kant's Philosophical Development". The Stanford Encyclopedia of Philosophy (winter 2019 Edition), Edward N. Zalta (ed.), URL = <https://plato.stanford.edu/archives/win2019/entries/kantdevelopment/>.

Siahaan, A., et al. (2020). The Effect of Scientific Approach and Interpersonal Interaction of Islamic Education to Student Characters in Integrated Islamic School Al Hafiz Langkat District. Budapest International Research and Critics in Linguistics and Education (BirLE) Journal, P. 1281-1286.

Slade, S. (2017, Feb 12). What Do We Mean by Quality Education? HUFFPOST. Retrieved (on 10th Feb, 2020) from https://www.huffpost.com/entry/what-do-wemean-by-a-qual_b_9284130

Teddlie, C. B., \&Tashakkori, A. (2009). Foundations of Mixed Methods Research: Integrating Quantitative and Qualitative Approaches to Social and BehaviouralSciences.Los Angeles, CA: Sage.

Weissbourd, R. (2003). Moral Teachers, Moral Students. Educational Leadership. 60(6), 611. Retrieved from http://www.ascd.org/publications/educationalleadership/mar03/vol60/num06/Moral-Teachers,-Moral-Students.aspx

Wulandari, U.N., et al. (2020). The Influence of Cooperative Learning Models and Learning Motivation on the Skills of Reading Students in Elementary School 101883 Tanjung Morawa Sub-District. Budapest International Research and Critics in Linguistics and Education (BirLE) Journal, P. 1311-1321. 